LVAD placement should be delayed in the setting of an acute infarct involving the LV apex. ${ }^{4}$ In the case of postMI-VSD with extensive infarction and a high risk of biventricular failure, a TAH should be implanted.

In an experienced mechanical circulatory support program, a 30-day survival rate of $74 \%$ can be achieved after TAH placement in patients with acute biventricular failure. ${ }^{5}$ However, the long-term results and quality of life will be severely impaired by hemolysis, infections, stroke, noise, and a bulky driver. Our presented technique might supersede the need for TAH placement in patients with post-MI-VSD.

\section{References}

1. Birnbaum Y, Fishbein MC, Blanche C, Siegel RJ. Ventricular septal rupture after acute myocardial infarction. $N$ Engl J Med. 2002;347:1426-32.

2. Deuse T, Schirmer J, Kubik M, Reichenspurner H. Isolated permanent right ventricular assistance using the HVAD continuous-flow pump. Ann Thorac Surg. 2013;95:1434-6

3. Fukushima S, Tesar PJ, Jalali H, Clarke AJ, Sharma H, Choudhary J, et al. Determinants of in-hospital and long-term surgical outcomes after repair of postinfarction ventricular septal rupture. J Thorac Cardiovasc Surg. 2010;140:59-65.

4. Feldman D, Pamboukian SV, Teuteberg JJ, Birks E, Lietz K, Moore SA, et al. The 2013 International Society for Heart and Lung Transplantation Guidelines for mechanical circulatory support: executive summary. J Heart Lung Transplant. 2013; 32:157-87

5. Ashfaq A, Jaroszewski DE, Pajaro OE, Arabia FA. The role of the total artificial heart in the treatment of post-myocardial infarction ventricular septal defect. J Thorac Cardiovasc Surg. 2013;145:e25-6.

\title{
Bilateral pulmonary artery banding with ligation clips: A novel technique resistant to residual stenosis
}

\author{
Yukihiro Kaneko, PhD, Ikuya Achiwa, MD, Hiroyuki Morishita, MD, and Miyuki Shibata, MD, Tokyo, \\ Japan
}

Bilateral pulmonary artery (PA) banding (BPAB) is a less invasive alternative to the Norwood procedure for hypoplastic left heart syndrome (HLHS) and related defects. Conventional BPAB, that is, bilateral PA narrowing achieved with expanded polytetrafluoroethylene tape, has its drawbacks, including high risks of residual PA stenosis after debanding and difficulty in attaining laterally balanced degree of banding. ${ }^{1,2}$ Conventional BPAB, which produces circular narrowing, inevitably reduces PA perimeter significantly. If PA narrowing could be attained with no or minimal reduction in its perimeter, the risk of residual PA stenosis might be reduced.

We have devised a novel BPAB technique whereby ligation clips are halfway closed into a rhombic shape to narrow bilateral PAs. Four ligation clip applicators with small stoppers within the jaws (Hemi Closure; Midorija Sugiura, Tokyo, Japan) were manufactured to transform a ligation clip (Horizon clip ML; Teleflex Medical Inc,

From the Division of Cardiovascular Surgery, National Medical Center for Children and Mothers, Tokyo, Japan.

Disclosures: Authors have nothing to disclose with regard to commercial support.

Received for publication Jan 23, 2014; accepted for publication Jan 31, 2014; available ahead of print March 15, 2014.

Address for reprints: Yukihiro Kaneko, PhD, Division of Cardiovascular Surgery, National Medical Center for Children and Mothers, 2-10-1, Okura, Setagaya-ku,

Tokyo 157-8535, Japan (E-mail: yukihirokaneko@ hotmail.com).

J Thorac Cardiovasc Surg 2014;147:1984-5

$0022-5223 / \$ 36.00$

Copyright (c) 2014 by The American Association for Thoracic Surgery

http://dx.doi.org/10.1016/j.jtcvs.2014.01.042
Research Triangle Park, NC) into a rhombic shape. Each applicator had a different length of stopper to transform the clip into a rhombic shape with an internal diagonal of either 1.0, 1.2, 1.4, or $1.6 \mathrm{~mm}$ (Figure 1).

At surgery, bilateral PAs were exposed through a median sternotomy and encircled with heavy threads. By gently pulling the threads, ligation clips were applied around both PAs. When the degree of banding was deemed inappropriate by oximetry or ultrasound, the clip was taken out with a clip remover (Hemoclip remover; Teleflex Medical) and replaced with a different sized clip. ${ }^{2}$

The novel BPAB technique was used in 8 neonates with HLHS and 7 high-risk neonates with congenital heart defects other than HLHS. Age at operation ranged from 1 to 15 days (median, 3 days). For more precise adjustment of banding, a clip applicator sized $1.3 \mathrm{~mm}$ was

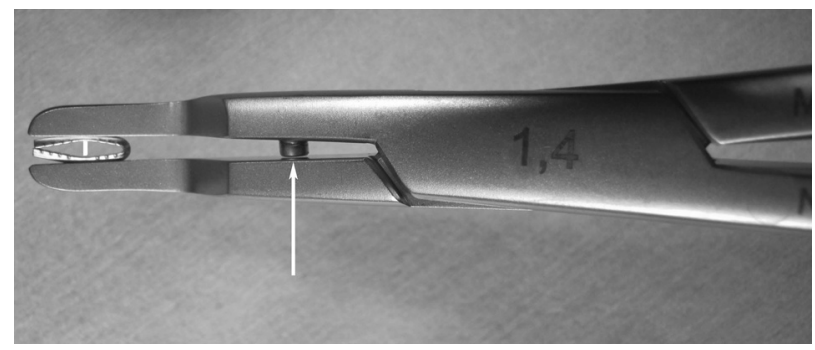

FIGURE 1. A clip applicator with a stopper within the jaw (white arrow) transforms the ligation clip into a rhombus with a shorter internal diagonal of $1.4 \mathrm{~mm}$ (indicated by white line). 


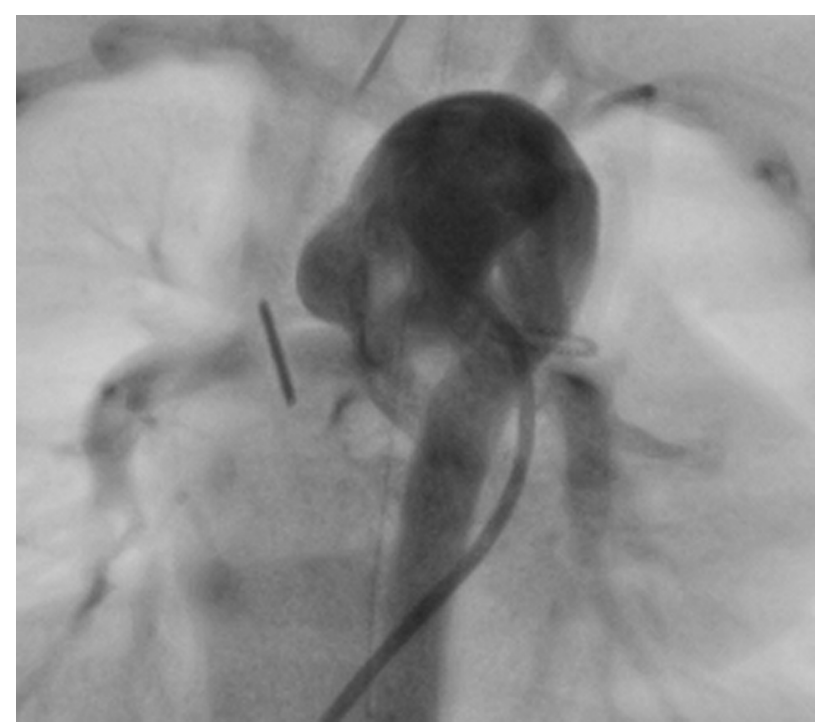

FIGURE 2. Pulmonary arteriography in a patient with hypoplastic left heart syndrome after bilateral pulmonary artery banding with clips. The pulmonary artery portions thinned by the clips appear translucent. The width of the pulmonary arteries is not reduced by the clips.

introduced in the last 3 of the 15 operations. For the right PA, clips sized 1.2, 1.3, and $1.4 \mathrm{~mm}$ were used in 6,3 , and 6 patients, respectively. For the left PA, clips sized 1.2 and $1.4 \mathrm{~mm}$ were used in 12 and 3 patients, respectively. Further intervention for a patient with HLHS and multiple extracardiac anomalies was refused by that patient's guardians. The remaining 14 patients went on to undergo second-stage surgery entailing clip removal. The PAs appeared to revert to adequate size after clip removal. No further enlargement of the PAs was required during surgery in any of the patients, although 1 patient who had clips in place for 284 days did require percutaneous balloon pulmonary arterioplasty for residual PA stenosis 4 months after debanding and truncus arteriosus repair. The remaining 13 patients who had clips in place for 11 to 152 days (median, 93 days) were free of residual PA stenosis 2 to 28 months after clip removal (median, 15 months).

Although we have introduced a novel BPAB technique, the idea of using noncircular PA banding to reduce residual PA stenosis is not new. A telemetrically adjustable device (FloWatch-PAB; EndoArt, Lausanne, Switzerland) was manufactured to narrow the pulmonary trunk by deforming it into a banana-shape. ${ }^{3}$ The pulmonary trunk was reported to revert to adequate size after removal of the FloWatch-PAB, rendering pulmonary trunk reconstruction unnecessary. Because of its bulk, however, the FloWatch-PAB is not applicable to BPAB. As such, our new technique will help fill that void. To our knowledge, this is the first report of a noncircular BPAB.

The benefits of using clips for BPAB are twofold. First, the rhombic clip reduces PA cross-sectional area significantly with minimal reduction of PA perimeter (Figure 2). The PA is therefore expected to revert to adequate size after clip removal. Second, clips assume a similar and predetermined shape by using the same applicator, thus allowing a constant degree of banding. In this way, laterally symmetric banding can be made easily. As reported elsewhere, histologic studies in beagles of PAs subjected to BPAB with clips showed less intimal proliferation and subintimal edema than did those subjected to conventional BPAB. ${ }^{4}$ Our clinical experience of BPAB with clips indicates that the adhesion around PAs in second-stage surgery is less dense than that seen after conventional BPAB, thereby allowing easier dissection. Also, due to its sharp vertex protruding from the PA surface, the clip is easier to remove than conventional BPAB tapes embedded around the PA. We believe that our new, facile BPAB technique may reduce residual PA stenosis and help achieve a laterally balanced degree of banding.

We thank Dr Julian Tang from the Department of Education for Clinical Research, National Center for Child Health and Development, for editing the manuscript.

\section{References}

1. Davies RR, Radtke WA, Klenk D, Pizarro C. Bilateral pulmonary arterial banding results in an increased need for subsequent pulmonary artery interventions. J Thorac Cardiovasc Surg. 2014;147:706-12.

2. Kitahori K, Murakami A, Takaoka T, Takamoto S, Ono M. Precise evaluation of bilateral pulmonary artery banding for initial palliation in high-risk hypoplastic left heart syndrome. J Thorac Cardiovasc Surg. 2010; 140:1084-91

3. Corno AF, Prosi M, Fridez P, Zunino P, Quarteroni A, von Segesser LK The non-circular shape of FloWatch-PAB prevents the need for pulmonary artery reconstruction after banding. Computational fluid dynamics and clinical correlations. Eur J Cardiothorac Surg. 2006;29:93-9

4. Achiwa I, Hirata Y, Kimura M, Nakazawa A, Nakano N, Kaneko Y [New technique of bilateral pulmonary artery banding using half-closed surgical clips; an experimental study]. Kyobu Geka. 2011;64:798-802. Japanese. 